\title{
Equilibrium and kinetic studies of the adsorption of antibiotics from aqueous solutions onto powdered zeolites
}

\author{
Diana Nara Ribeiro de Sousa ${ }^{\mathrm{a}, \mathrm{b}}$, Sara Insa ${ }^{\mathrm{b}}$, Antonio Aparecido Mozeto a \\ Mira Petrovic ${ }^{\text {b, c }}$, Thiago Faheina Chaves ${ }^{\text {d }}$, Pedro Sergio Fadini ${ }^{\text {a, * }}$ \\ a Laboratório de Biogeoquímica Ambiental (LBGqA), Departamento de Química, Universidade Federal de São Carlos (UFSCar), Rodovia Washington Luís, km \\ 235, 13565-905, São Carlos, SP, Brazil \\ ${ }^{\mathrm{b}}$ Catalan Institute for Water Research (ICRA), Scientific and Technological Park of the University of Girona, $\mathrm{H}_{2} \mathrm{O}$ Building, Emili Grahit 101, 17003, Girona, \\ Spain \\ ${ }^{\mathrm{c}}$ Catalan Institution for Research and Advanced Studies (ICREA), Passeig de Lluís Companys 23, 08010, Barcelona, Spain \\ ${ }^{d}$ Instituto de Química, UNESP-Univ. Estadual Paulista, Rua Prof. Francisco Degni 55, 14800-060, Araraquara, SP, Brazil
}

\section{H I G H L I G H T S}

- Fast and effective removal of antibiotics in aqueous media by FAU zeolite.

- PH-dependent adsorption of azithromycin and ofloxacin by FAU zeolite.

- Low competitive effect on adsorption efficiency of mixed antibiotics onto FAU zeolite.

- Good adsorption of antibiotics from a wastewater sample onto FAU zeolite.

\section{A R T I C L E I N F O}

\section{Article history:}

Received 11 January 2018

Received in revised form

9 April 2018

Accepted 15 April 2018

Available online 17 April 2018

Handling Editor: Klaus Kümmerer

\section{Keywords:}

Zeolite

Antibiotics

Fast adsorption

Effective removal

\begin{abstract}
A B S T R A C T
The performances of two FAU-type zeolites with different $\mathrm{SiO}_{2} / \mathrm{Al}_{2} \mathrm{O}_{3}$ ratios were evaluated for the removal of antibiotics of three different classes, namely azithromycin, ofloxacin, and sulfamethoxazole, from aqueous solutions. Commercial zeolites were used, without any previous treatment. Use of a small adsorbent dosage resulted in fast antibiotic adsorption that followed pseudo-second order kinetics. The removals of azithromycin and sulfamethoxazole were highly $\mathrm{pH}$-dependent, with low removal percentages observed under acid $(\mathrm{pH} 2.5-4.5)$ and basic $(\mathrm{pH} 8.5-10.5)$ conditions, respectively. The Freundlich isotherm model provided the best fits to the adsorption data. The adsorption mechanisms appeared to involve both electrostatic and H-bonding interactions. Using an antibiotics mixture, percentage removals of azithromycin and ofloxacin onto the zeolites of up to $79 \%$ were obtained. Both materials presented good adsorption ( $>50 \%$ ) of azithromycin and ofloxacin from a real sample of effluent wastewater. The results showed that zeolites with FAU structure can be used as effective adsorbents for the removal of antibiotics with different physicochemical properties, including molecules with large volumes, such as azithromycin.
\end{abstract}

๑) 2018 Elsevier Ltd. All rights reserved.

\section{Introduction}

Antibiotics can be considered a special class of pharmaceuticals, due to the risks associated with their presence in the environment, especially regarding the development of bacterial resistance

\footnotetext{
* Corresponding author.

E-mail addresses: dnrsousa@yahoo.com.br (D.N.R. de Sousa), sinsa@icra.cat (S. Insa), amozeto@ufscar.br (A.A. Mozeto), mpetrovic@icra.cat (M. Petrovic) thiago_faheina@yahoo.com.br (T.F. Chaves), psfadini@ufscar.br (P.S. Fadini).
}

(Daughton and Ternesa, 1999; Fent et al., 2006). The high consumption of antibiotics for various purposes, together with the inefficient removal of these molecules in wastewater treatment plants (WWTP), has led to their ubiquitous presence in many aqueous matrices (García-galán et al., 2011; Gros et al., 2013; Michael et al., 2012). In light of these facts, new technologies have been proposed for the elimination of these compounds, in combination with conventional treatments.

Various processes can be used to remove antibiotics from aqueous media (Homem and Santos, 2011). Among these, 
adsorption techniques have been successfully applied for removal of different classes of pharmaceuticals (Sophia A. and Lima, 2018; Yu et al., 2016). Although, activated carbons are among the most commonly used adsorbents for the removal of organic contaminants, zeolites have been effectively employed for the removal of several class of emerging compounds (Perego et al., 2013).

Zeolites are crystalline materials derived from natural or synthetic origins, with structures characterized by a framework of $\mathrm{SiO}_{4}$ and $\mathrm{AlO}_{4}$ linked together by oxygen atoms and surrounding a cation. The zeolite crystals have pores of molecular dimensions, with a system of channels and cavities ranging from 0.3 to $1.5 \mathrm{~nm}$ in size, which may be occupied by water molecules, salts, or other adsorbates (Cundy and Coxa, 2003). Faujasite-type zeolites (FAU) are characterized by a three-dimensional channel system with 12 membered-ring pores $(7.1 \AA \times 7.0 \AA$ ), with a pore structure characterized by approximately $12 \AA$ diameter cages (Weitkamp, 2000; Baerlocher et al., 2017). The pore size is one of the most important characteristics of these materials, as the opening limits the transfer of substances into the intracrystalline space, leading to the process known as molecular sieving (Davis and Lobo, 1992).

Zeolites can offer superior selectivity in terms of competitive adsorption between organic micropollutants and natural organic matter (NOM), compared to activated carbons (Pelekani and Snoeyink, 1999; Ebie et al., 2001; de Ridder et al., 2012). Furthermore, due their high stability over a wide range of temperatures and acidic conditions, regeneration of zeolites can be performed without significative losses of material (Cincinelli et al., 2015).

FAU-type zeolites has been investigated for adsorptive removal of sulfonamide (Fukahori et al., 2011; Blasioli et al., 2014) and fluoroquinolones (Martucci et al., 2012; Genç and Dogan, 2015) antibiotics in aqueous solutions at $\mathrm{mg} \mathrm{L}^{-1}$ concentrations, which are significantly higher than environmentally relevant levels ( $\mathrm{ng} \mathrm{L}^{-1}-$ $\mu \mathrm{g} \mathrm{L}^{-1}$ ). However, no data was reported to the removal of the macrolide antibiotic azithromycin, enlisted in the first watch list for European Union monitoring, defined in the Decision 2015/495/EU (Decision, 2015).

This study investigates the adsorption of three antibiotics from different classes namely azithromycin (AZM), ofloxacin (OFX) and sulfamethoxazole (SMX) onto two commercially available powdered FAU zeolites. The adsorption efficiencies of the antibiotics onto the zeolites were studied at $\mu \mathrm{g} \mathrm{L}^{-1}$ levels, considering the $\mathrm{pH}$ of the antibiotics solution. Isotherm and kinetic models were applied in order to understand the main mechanisms involved in the adsorption processes. Finally, the zeolites were used for the removal of contaminants from a WWTP effluent sample, in order to determine the effect of interferents present in a real complex matrix, which have been relatively scarce.

\section{Experimental}

\subsection{Chemicals and reagents}

High purity ( $>95 \%$ ) individual standards of the antibiotics azithromycin (AZM), ofloxacin (OFX), and sulfamethoxazole (SMX) were purchased from Sigma-Aldrich. For use as internal standards, the isotopically labeled compounds azithromycin- $\mathrm{d}_{3}$ and sulfamethoxazole- $\mathrm{d}_{4}$ were purchased from Toronto Research Chemicals (Ontario, Canada), and ofloxacin- $\mathrm{d}_{3}$ was purchased from SigmaAldrich. These antibiotics have been chosen considering their widespread consumption and occurrence in water bodies (Gros et al., 2013; Carvalho and Santos, 2016). The chemical structures and some physicochemical properties of antibiotics are shown in Table 1. Individual stock standards and isotopically labeled internal standard solutions were prepared in methanol, at concentrations of $1000 \mathrm{mg} \mathrm{L}^{-1}$, and were stored at $-20^{\circ} \mathrm{C}$. Individual working standard solutions were prepared in methanol by appropriate dilution of the stock standard solutions. All the solvents used for preparation of the stock solutions and in the chromatographic analyses were HPLC-grade and were obtained from Fisher Chemical. Formic acid used in the mobile phase was Emsure ${ }^{\circledR}$ grade, supplied by Merck (Finland).

\subsection{Preparation and characterization of adsorbents}

Two powdered FAU zeolites with different $\mathrm{SiO}_{2} / \mathrm{Al}_{2} \mathrm{O}_{3}$ ratios, denoted FAU- 1 and FAU-2, were kindly provided by Zeolyst International. The zeolites were supplied in protonated forms (acid form), and the $\mathrm{Na}_{2} \mathrm{O}$ contents were lower than $0.05 \%$.

Powder X-ray diffraction patterns of the samples were obtained using a Siemens D5000 diffractometer and $\mathrm{Cu} \mathrm{K} \alpha$ radiation selected by a curved graphite monochromator. Data were collected in the 2 theta range from 5 to 40 using a step size of 0.02 and counting time of $2 \mathrm{~s}$. The zeolite crystals size and morphology were observed by scanning electron micrographs on a Philips XL30 FEG microscope. The samples were previously deposited on aluminum sample holder and covered with gold.

For all the adsorption experiments, the zeolites were previously dried in an oven at $100{ }^{\circ} \mathrm{C}$ during $12 \mathrm{~h}$, in order to remove surface water and improve the accuracy of weighing.

\subsection{Kinetic and equilibrium experiments}

The adsorption experiments were conducted in batch mode in a series of $50 \mathrm{~mL}$ glass bottles containing $30 \mathrm{~mL}$ of ultrapure water spiked with an initial $100 \mu \mathrm{g} \mathrm{L}^{-1}$ concentration of the individual antibiotics. These concentrations, which were still relatively high compared to the levels detected in environmental matrices, were selected in order to obtain adequate antibiotics concentrations during the kinetic and adsorption isotherm experiments, enabling detection of the remaining antibiotics concentrations without any need for a previous preconcentration step. Kinetic tests were conducted (in triplicate) for each individual antibiotic, in order to identify the optimum equilibrium time. The solutions were kept under stirring, with contact times of from 0 to $360 \mathrm{~min}$. For each time, a $1.5 \mathrm{~mL}$ aliquot was collected from the system. The solids were separated from the aqueous solutions by filtration through $13 \mathrm{~mm}$ syringe filters containing $0.20 \mu \mathrm{m}$ PTFE membranes (Merck Millipore, Carrigtwohill, Co. Cork, Ireland), and the antibiotics concentrations in the aqueous solutions were determined by HPLCESI-MS/MS. No significant losses were observed during the filtration step with the PTFE membrane filters. Aliquots of $1 \mathrm{~mL}$ of the filtered samples were transferred to glass vials, followed by addition of $50 \mu \mathrm{L}$ of a mixture of the three isotopically labeled internal standards at concentrations of $1 \mathrm{mg} \mathrm{L}^{-1}$. One additional glass bottle was submitted to the full procedure under the same conditions, in order to evaluate possible degradation of the compounds, with aliquots being removed analysis at every time interval, and no significant losses were observed.

The adsorption efficiency (\%) and the amount of antibiotic adsorbed at equilibrium per unit weight of adsorbent at equilibrium $\left(q_{t}\right)$, were calculated as show in, Equations (1) and (2), respectively:

Adsorption $(\%)=\frac{\left(C_{0}-C_{t}\right)}{C_{0}} \times 100$

$q_{t}=\frac{C_{o}-C_{t}}{W} \times V$

where $C_{0}$ is the initial concentration of antibiotic solution $\left(\mathrm{mg} \mathrm{L}^{-1}\right)$, 
Table 1

Characteristics of the investigated antibiotics.

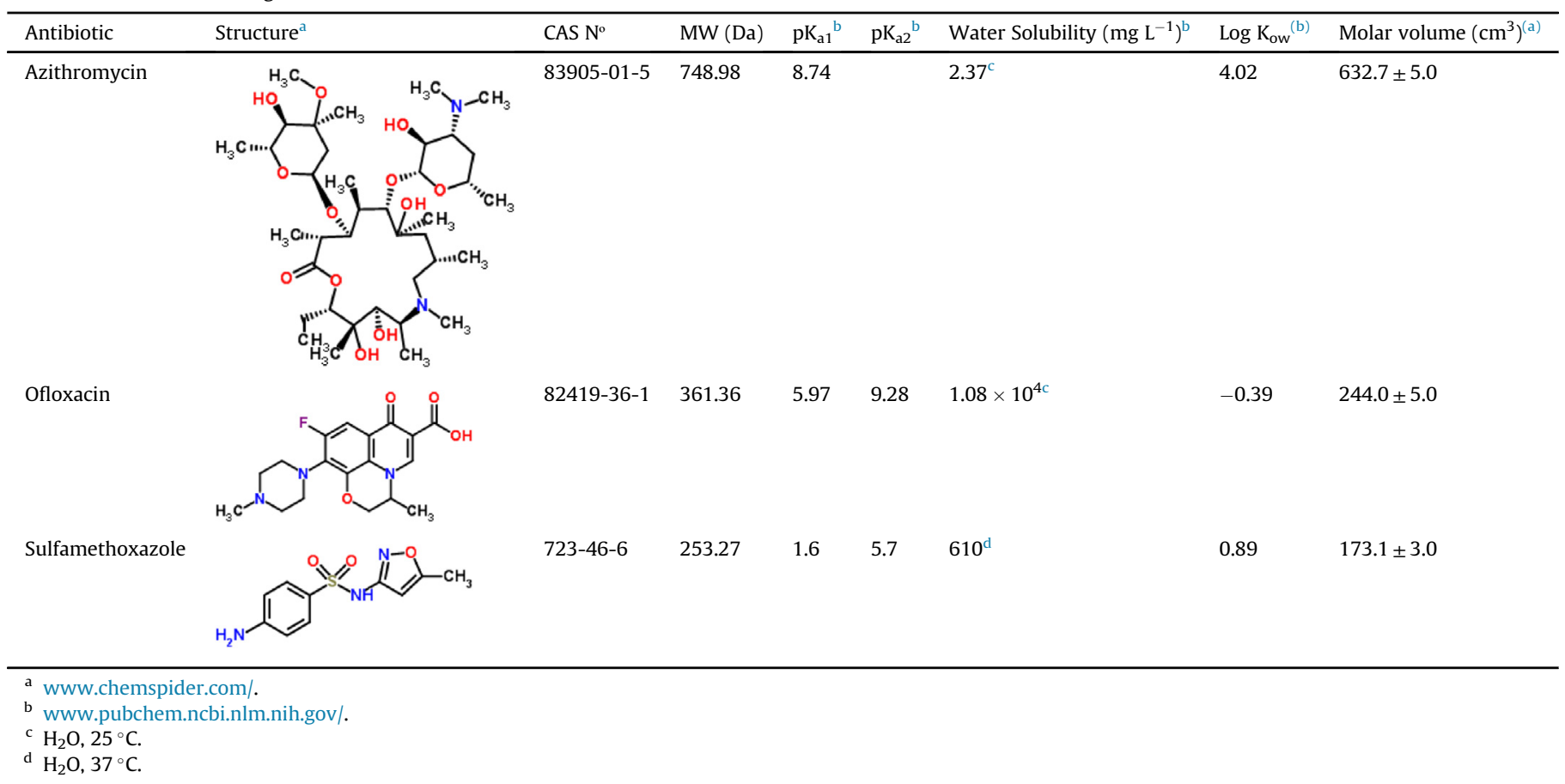

$C_{t}$ is the concentration of antibiotic solution $\left(\mathrm{mg} \mathrm{L}^{-1}\right)$ after time $t$ of contact with zeolites, $\mathrm{V}$ is the volume of solution (L), and $\mathrm{W}$ is the amount of zeolite $(\mathrm{g})$ taken into the flask.

For evaluation of the kinetics, a pseudo-second order model was used, according to Equations (3) and (4) (Azizian, 2004):

$\frac{t}{q_{t}}=\frac{1}{k q_{e}^{2}}+\frac{1}{q_{e}} t$

$h=k q_{e}^{2}$

where $q_{e}$ is the amount of solute adsorbed per amount of sorbent at equilibrium ( $\left.\mathrm{mg} \mathrm{g}^{-1}\right), q_{t}$ is the amount of solute adsorbed per amount of sorbent at any time $\left(\mathrm{mg} \mathrm{g}^{-1}\right), k_{2}$ is the adsorption rate constant $\left(\mathrm{g} \mathrm{mg}^{-1} \mathrm{~min}^{-1}\right), h$ is the initial adsorption rate $\left(\mathrm{mg} \mathrm{g}^{-1}\right.$ $\left.\min ^{-1}\right)$, and $t$ is the time ( $\mathrm{min}$ ).

Adsorption isotherms were produced by varying the individual initial antibiotic concentrations from 10 to $400 \mu \mathrm{g} \mathrm{L}^{-1}$, with a fixed adsorbent concentration. The adsorption isotherm data were interpreted using the Langmuir (Equation (5)) and Freundlich (Equation (6)) models to determine the isotherm parameters. Fittings of the experimental data to non-linear isothermal models, were determined using Origin Pro 2015:

$q_{e}=\frac{q_{m} K_{L} C_{e}}{\left(1+K_{L} C_{e}\right)}$

$q_{e}=K_{f} C_{e}^{1 / n}$

where $q_{e}$ is the amount of solute adsorbed per amount of sorbent at equilibrium ( $\mathrm{mg} \mathrm{g}^{-1}$ ), $q_{m}$ is the maximum amount of solute adsorbed per amount of sorbent at any time $\left(\mathrm{mg} \mathrm{g}^{-1}\right), C_{e}$ is the concentration in the solution at equilibrium $\left(\mathrm{mg} \mathrm{L}^{-1}\right), K_{L}$ is the Langmuir coefficient $\left(\mathrm{L} \mathrm{mg}^{-1}\right)$, and $K_{f}$ and $n$ are Freundlich constants related to the adsorption intensity (Foo and Hameed, 2010).
The $\mathrm{pH}$ dependence of the adsorption was also investigated in batch mode, using a fixed initial antibiotic concentration of $100 \mu \mathrm{g} \mathrm{L}^{-1}$ and varying the $\mathrm{pH}$ from 2.5 to 10.5 . This range of $\mathrm{pH}$ values was chosen based on the $\mathrm{pK}_{\mathrm{a}}$ values for the compounds studied (Table 1). The $\mathrm{pH}$ of the ultrapure water was adjusted prior to addition of the antibiotic and the zeolite, using a few drops of diluted solutions from a $1 \mathrm{~mol} \mathrm{~L}^{-1}$ hydrochloric acid (Panreac, Barcelona, Spain) or $1 \mathrm{~mol} \mathrm{~L}^{-1}$ sodium hydroxide (Scharlab, Gato Perez, Spain). The pH was measured with a pH meter (GLP-21, Crison, Barcelona, Spain). All the experiments were carried out in triplicate and the results were reported as means and standard deviations.

\subsection{HPLC-ESI-MS/MS analyses}

The samples were analyzed using an EQuan MAX system coupled to a TSQ Vantage triple quadrupole mass spectrometer equipped with an electrospray source (ESI), both acquired from Thermo Fisher Scientific. Chromatographic separation was performed using a Kinetex biphenyl column $(2.6 \mu \mathrm{m}$ particle size, $100 \AA, 50 \mathrm{~mm} \times 2.1 \mathrm{~mm}$ i. d.) from Phenomenex. The eluents, adapted from previous work (Farré et al., 2016), were methanol (eluent $\mathrm{A}$ ) and $0.1 \%$ aqueous formic acid solution (eluent $\mathrm{B}$ ), at a flow rate of $400 \mu \mathrm{L} \mathrm{min}^{-1}$. The initial gradient elution condition was $30 \% \mathrm{~A}$, held for $0.5 \mathrm{~min}$, followed by a linear increase to $100 \% \mathrm{~A}$ in $4.5 \mathrm{~min}$, and then maintaining isocratic conditions for $2 \mathrm{~min}$. At the end of the run, the initial conditions were restored in $2 \mathrm{~min}$. The total run time was $8.5 \mathrm{~min}$ and the sample injection volume was $10 \mu \mathrm{L}$.

For the analysis of wastewater samples, a fully automated online preconcentration sampling system was used. The samples were first preconcentrated on a Hypersil GOLD aQ column (20 $\mathrm{mm} \times 2.1 \mathrm{~mm}, 12 \mu \mathrm{m}$ particle size; Thermo Fisher Scientific), upstream of the chromatographic column described above. The flow rate for the loading step was $1750 \mu \mathrm{L} \mathrm{min}^{-1}$. The optimal conditions for loading were an initial eluent composed of $2 \%$ 
methanol and 98\% HPLC-grade water held for $1.25 \mathrm{~min}$, followed by a linear increase to $50 \%$ methanol during $1 \mathrm{~min}$, an increase to $100 \%$ methanol in $2.25 \mathrm{~min}$, and isocratic conditions for $2 \mathrm{~min}$. At the end of the run, the initial conditions were restored. The injection volume was set at $2 \mathrm{~mL}$.

The MS/MS parameters were optimized by direct infusion of individual standard solutions of each compound. The settings for the source parameters were determined by flow injection analysis and were as follows: ion spray voltage of $3.0 \mathrm{kV}$, vaporizer temperature of $350^{\circ} \mathrm{C}$, and capillary temperature of $300^{\circ} \mathrm{C}$. For detection purposes, two transitions were recorded in selected reaction monitoring (SRM) mode for each compound. The first transition (SRM1) was used for quantification and the second (SRM2) was used for confirmation. A summary of the optimum SRM transitions and conditions is provided in Table S1.

A ten-point calibration set was freshly prepared by adding different amounts of working standard solution to the mobile phase (methanol:water, 30:70), in the concentration range from 0.1 to $500 \mu \mathrm{g} \mathrm{L}^{-1}$ for all analytes. Quantitation was performed using the internal standards method, employing the deuterated compounds at a fixed concentration of $50 \mathrm{ng} \mathrm{L}^{-1}$, with calibration curves constructed using the relative response ratio (calculated as the area of the analyte standard divided by the area of the internal standard) as a function of the analyte concentration. Linear responses were observed for all the analytes in the concentration range used $\mathrm{R}^{2}>0.99$. The performance of the method was evaluated in terms of precision, determined as the relative standard deviation (\%RSD) calculated from repeated injections of a standard solution on the same day (repeatability) and on different days (reproducibility). The instrumental detection limits (IDLs) were estimated from the signal-to-noise ratios $(\mathrm{S} / \mathrm{N}=3)$ obtained for low concentration calibration standards. All the data were acquired using Xcalibur 2.2 software and were processed using Trace Finder EFS 3.1. Table S2 summarizes the method performance parameter values.

\subsection{Wastewater sample collection and preparation}

Wastewater effluent samples were collected from the Girona WWTP (Catalonia, Spain). In addition to urban and domestic wastewater, this WWTP receives the wastewater from a hospital in the Girona region, and is designed for 206,250 population equivalents (Gros et al., 2013). For the adsorption tests, a $30 \mathrm{~mL}$ wastewater samples were previously filtered through $0.45 \mu \mathrm{m}$ nylon membrane filters (both from Merck Millipore, Carrigtwohill, Ireland), the zeolite was added to achieve a concentration of $10 \mathrm{mg} \mathrm{L}^{-1}$, and the sample was kept under stirring for $2 \mathrm{~h}$. A $10 \mathrm{~mL}$ volume of the sample was collected, filtered through $0.20 \mu \mathrm{m}$ PTFE syringe filter membranes, placed in an amber SPE vial (Supelco) and spiked with a mixture of the three internal standards in order to achieve a concentration of $200 \mathrm{ng} \mathrm{L}^{-1}$, followed by analysis as described in Section 2.4. The $\mathrm{pH}$ was measured with a $\mathrm{pH}$ meter (GLP-21, Crison, Barcelona, Spain). Aqueous total organic carbon (TOC) concentration was determined with a TOC-Model TOC-V $\mathrm{VSH}_{\mathrm{CH}}$ (Shimadzu). The concentration of major cations $\left(\mathrm{Ca}^{2+}, \mathrm{Mg}^{2+}, \mathrm{Na}^{+}\right.$, $\mathrm{NH}_{4}^{+}$) were measured using ion chromatography on a Dionex ${ }^{\mathrm{TM}}$ ICS5000 .

\section{Results and discussion}

The main objectives of this work included evaluation of the performance of two zeolites with similar structures and different $\mathrm{SiO}_{2} / \mathrm{Al}_{2} \mathrm{O}_{3}$ ratios, which were used for the adsorption of three antibiotics from different compound classes. For this purpose, the adsorption mechanisms were investigated using kinetic and isothermal models. The effect of $\mathrm{pH}$ on the adsorption process was evaluated by varying the $\mathrm{pH}$ of the antibiotic solution, based on the $\mathrm{pK}_{\mathrm{a}}$ values of the molecules studied. In addition, the zeolites were applied in removal tests using a sample of wastewater effluent.

\subsection{Adsorbent characterization}

Table 2 shows the physicochemical characteristics of the zeolites used in this study, according to the analysis certificates provided by Zeolyst. Both zeolites presented $\mathrm{H}$-form structures and had similar specific surface areas, this feature is desired to more clearly evaluate the effect of $\mathrm{SiO}_{2} / \mathrm{Al}_{2} \mathrm{O}_{3}$ ratio (SAR) on the adsorption process.

The X-ray diffraction patterns (Fig. 1) showed typical profiles FAU framework, with well-resolved peaks at $2 \theta$ of between $5^{\circ}$ and $40^{\circ}$, indicative of highly crystalline material (Holmberg et al., 2003; Chaves et al., 2012). No diffraction peaks were observed related to secondary zeolitic phases, showing that the material has only the FAU zeolitic phase. Comparing the samples FAU-1 and FAU-2, a small difference in the intensity of the diffraction reflections can be observed. This may be related to post-synthesis treatment to obtain the high silica FAU zeolite, i.e., FAU-2 with SAR 80 (Chen, 1999).

SEM images of FAU-1 and FAU-2 samples are shown in Fig. 2. The image of both FAU samples (Fig. 2) shows crystals with diameters between of $\sim 0.5-1.0 \mu \mathrm{m}$. The SEM image at higher magnification (Fig. 2b and d) clearly indicates the high crystallinity of samples, with well-defined octahedral crystalline habit characteristic of FAU-type zeolite (Kacirek and Lechert, 1975). Both zeolites presented a similar particle size distribution, corroborating with surface area analysis provided by Zeolyst (showed in Table 2).

\subsection{Adsorption kinetics}

Fig. 3 shows the adsorption efficiencies for the individual antibiotics on the two zeolites. The adsorbent concentrations used were $10 \mathrm{mg} \mathrm{L}^{-1}$ for AZM and OFX, and $500 \mathrm{mg} \mathrm{L}^{-1}$ for SMX. The three antibiotics showed fast adsorption onto the two zeolites, with equilibrium concentrations reached after $15-30 \mathrm{~min}$. The amount of antibiotic adsorbed per unit mass of zeolite $\left(\mathrm{q}_{\mathrm{t}}\right)$ as a function of contact time are show in Fig. S1. Different antibiotic molecules have been successfully removed using materials such as natural and synthetic zeolites with different types of structures, activated carbons, and mesoporous silica (Blasioli et al., 2014; Bui et al., 2013; Carrales-Alvarado et al., 2014). However, the great majority of the reported studies have targeted molecules with small sizes. Similar to our results (Martucci et al., 2012), obtained good adsorption efficiency in the removal of erythromycin, a macrolide antibiotic with similar structure to azithromycin, onto faujasite and mordenite zeolites. In addition, compared to other adsorbents such as activated carbons (Calisto et al., 2015) and mesoporous silica (Bui and Choi, 2009), the adsorbent dosages were considerably lower in this work with zeolites.

Table 3 provides the kinetic parameters for the antibiotics, obtained by fitting the data with pseudo-second order equations. For both zeolites, fitting of the experimental data using the pseudosecond order model resulted in determination coefficients higher than 0.99. For all the antibiotics and both zeolites, the adsorption was almost instantaneous, and no significant differences ( $\mathrm{p}>0.05)$ in the adsorption percentages were observed for contact times

Table 2

Characteristics of zeolites used in this study.

\begin{tabular}{lll}
\hline Property & FAU-1 & FAU-2 \\
\hline BET surface area $\left(\mathrm{m}^{2} \mathrm{~g}^{-1}\right)$ & 914 & 899 \\
$\mathrm{SiO}_{2} / \mathrm{Al}_{2} \mathrm{O}_{3}$ ratio, bulk & 30.62 & 82.59 \\
\hline
\end{tabular}




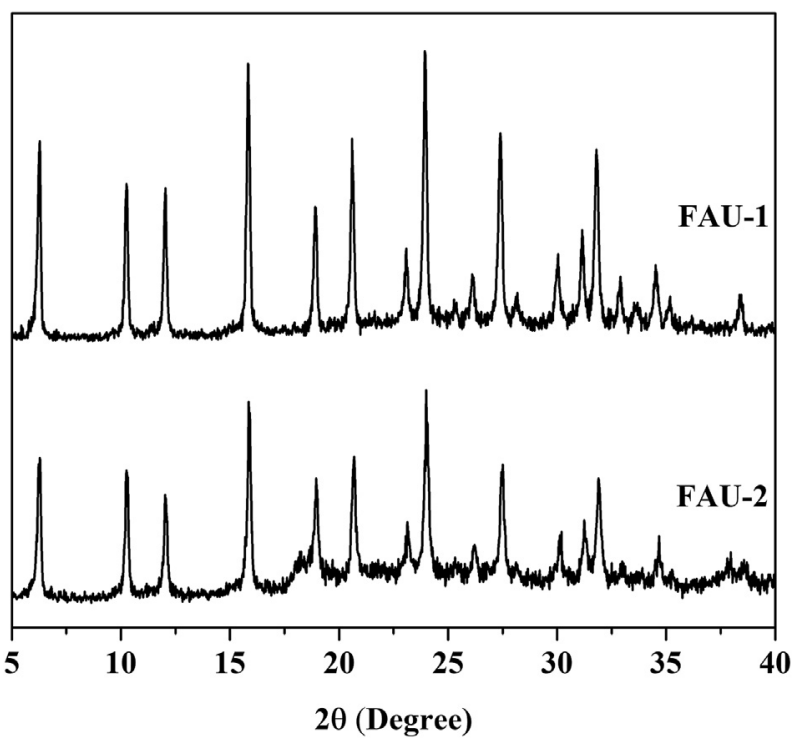

Fig. 1. X-ray diffractograms of the two zeolites used in this work.

longer than $30 \mathrm{~min}$.

For AZM, the pseudo-second order rate constant $(k)$ was higher for adsorption onto FAU-1 than onto FAU-2, in good agreement with the experimental data (Fig. 3). The same trend was observed for OFX, while SMX presented a higher value of $k$ for adsorption on FAU-2. Considering that the same initial antibiotic concentration was used $\left(100 \mu \mathrm{g} \mathrm{L}^{-1}\right)$, adsorption of SMX would require a higher adsorbent dosage in order to achieve an adsorption efficiency similar to those obtained for AZM and OFX.

The pseudo-second order model assumes that chemisorption is the dominant adsorption mechanism, with the sorption capacity being proportional to the number of active sites occupied on the adsorbent (Genç and Dogan, 2015). The higher adsorption and good fit of the pseudo-second order kinetic model for FAU-1 than for FAU-2 for AZM may be related to higher amount of aluminum (sites) present in FAU-1 (SAR 30). The proposed adsorption mechanisms will be discussed in more detail in the evaluation of $\mathrm{pH}$ effect and adsorption isotherms models. The results obtained here showed that both zeolites presented favorable kinetic behavior, enabling effective and fast adsorption of antibiotics with different physicochemical characteristics. These materials are therefore highly promising material for use in removal processes.

\subsection{Effect of $p H$ on antibiotic adsorption}

Fig. 4 and Fig. S2 show the adsorption behaviors of the three antibiotics on FAU-1 and FAU-2 at different $\mathrm{pH}$ values. The adsorption efficiency profile for the three antibiotics is similar for the two zeolites. The amount of adsorption onto the zeolites decreased at either low or high $\mathrm{pH}$ values, for AZM and SMX, respectively. On the contrary, OFX adsorption had no significant changes under $\mathrm{pH}$ range.

One important parameter that affects the equilibrium adsorption mechanism in zeolites is the interaction between the acid sites of the zeolite and the functional groups of the adsorbate. An $\mathrm{H}^{+}-$ zeolite, as used in the current study, can provide both acid Brønsted and Lewis type sites. Zeolite acidity increases in strength as the molar ratio of $\mathrm{SiO}_{2} / \mathrm{Al}_{2} \mathrm{O}_{3}$ decreases due the increase in $\left(\mathrm{AlO}_{\overline{4} / 2}\right)$ sites, which strengthens the electro-static filed in the zeolite and increases the number of acid sites (Kulprathipanja, 2010). It is important to mention that, a high density of $\left(\mathrm{AlO}_{4 / 2}^{-}\right)$sites in the zeolite framework could actually lower the acid strength and the reverse in acid strength can be explained by the dipolar repulsion of the neighbors $\left(\mathrm{AlO}_{4 / 2}^{-}\right)$sites (Gounder et al., 2012). However, even for the FAU-1 sample (SAR 30), we do not believe that the acidic strength is affected by the proximity of the $\left(\mathrm{AlO}_{4 / 2}^{-}\right)$sites. The Brønsted sites are typically structural ( $\equiv \mathrm{Si}-\mathrm{OH}-\mathrm{Al} \equiv)$ found into the zeolite microporous. The terminal $\equiv \mathrm{Si}-\mathrm{OH}$ there is on the surface of zeolite and can be protonated under acid conditions ( $\left.\equiv \mathrm{Si}-\mathrm{OH}_{2}^{+}\right)$and deprotonated under basic condition $\left(\equiv \mathrm{Si}-\mathrm{O}^{-}\right)$, resulting in the
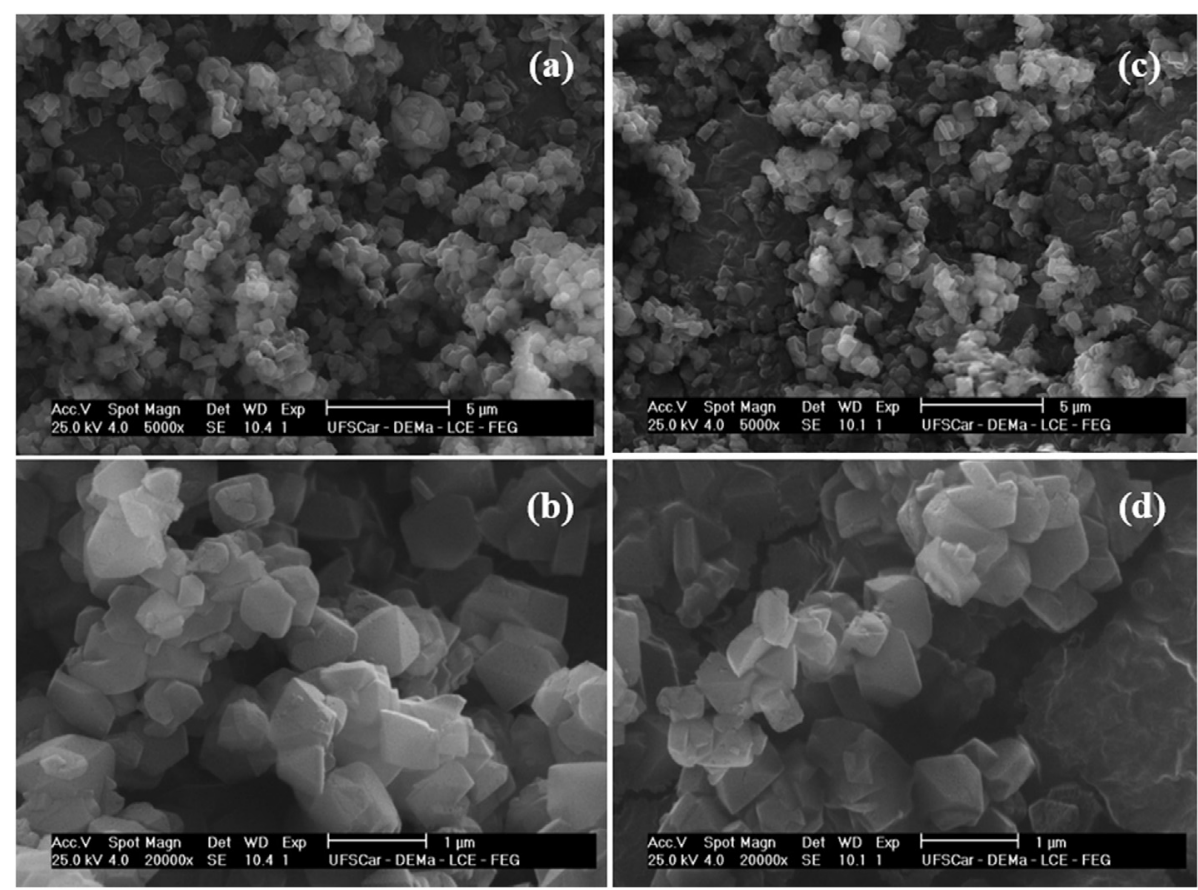

Fig. 2. SEM images of the FAU-1 (2a-2b) and FAU-2 (2c-2d) zeolites. 

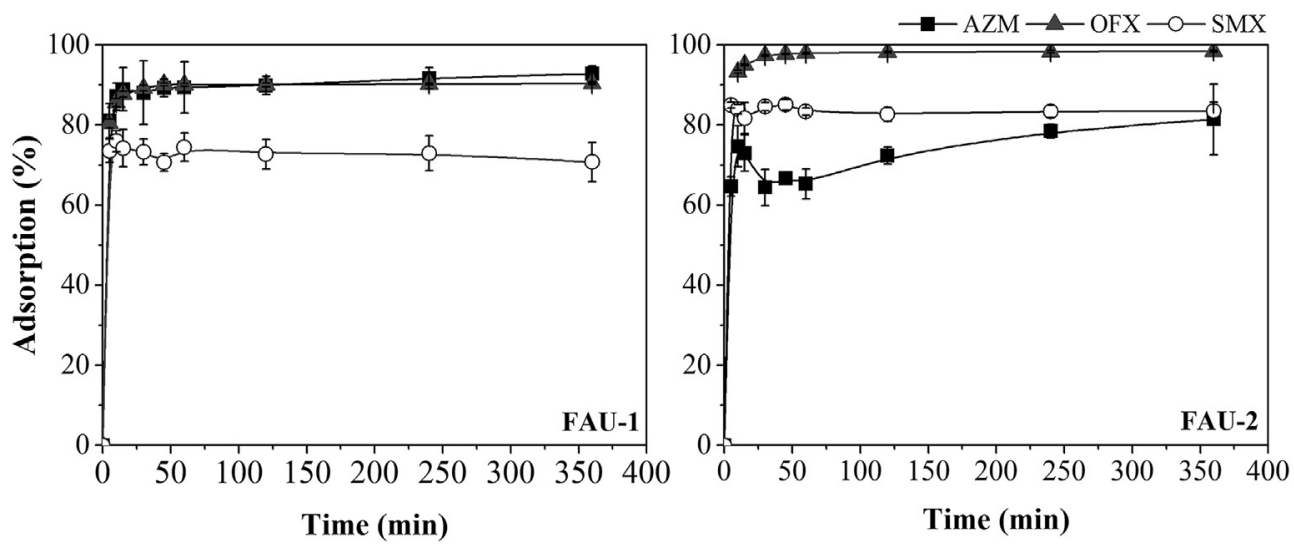

Fig. 3. Kinetic results of antibiotics adsorption onto FAU-1 and FAU-2.

Table 3

Kinetic parameters obtained using pseudo-second order kinetic equations to fit the experimental data for adsorption of the antibiotics onto FAU- 1 and FAU-2.

\begin{tabular}{|c|c|c|c|c|c|c|}
\hline Antibiotic & Zeolite & $\mathrm{q}_{\mathrm{e}}\left(\mathrm{mg} \mathrm{g}^{-1}\right)$ & $k\left(\mathrm{~g} \mathrm{mg}^{-1} \mathrm{~min}^{-1}\right)$ & $\mathrm{h}\left(\mathrm{mg} \mathrm{g}^{-1} \min ^{-1}\right)$ & $\mathrm{R}^{2}$ & $\mathrm{t}_{1 / 2}(\mathrm{~min})$ \\
\hline \multirow[t]{2}{*}{ AZM } & FAU-1 & 7.56 & 0.082 & 4.70 & 0.999 & 1.61 \\
\hline & FAU-2 & 6.16 & 0.024 & 0.89 & 0.997 & 6.89 \\
\hline \multirow[t]{2}{*}{ OFX } & FAU-1 & 6.99 & 0.327 & 16.0 & 1.000 & 0.44 \\
\hline & FAU-2 & 7.15 & 0.293 & 0.006 & 1.000 & 0.47 \\
\hline \multirow[t]{2}{*}{ SMX } & FAU-1 & 0.19 & 4.96 & 0.17 & 0.999 & 1.09 \\
\hline & FAU-2 & 0.16 & 59 & 1.49 & 1.000 & 0.10 \\
\hline
\end{tabular}

surface charge of zeolites (Yang et al., 2002; Kuzniatsova et al., 2007).

When the $\mathrm{pH}$ starts increasing from 2.5 the percentage ionization of SMX increases and the negative charge on zeolite also goes to increase due to equilibrium previously mentioned involving the surface silanol group. Thus, increasing number of ions of SMX goes on adsorbing via electrostatic interaction and H-bonding between the ionized and unionized molecules of SMX and $\equiv \mathrm{Si}-\mathrm{O}^{-}$groups on the zeolite surface (Fukahori et al., 2011). Furthermore, at pH higher than the $\mathrm{pKa}_{2}$ value of SMX (5.7), the dominant adsorbed species is the negatively charged form, so the adsorption mechanism involves repulsive electrostatic interaction, which explains the decreased adsorption efficiency at solution $\mathrm{pH}$ values of 8.5 and 10.5. Additionally, the acid Brønsted sites due the groups $\equiv \mathrm{Si}-\mathrm{OH}-\mathrm{Al} \equiv$ in the zeolite framework, can be easily de-protonated to form $\equiv \mathrm{Si}-\mathrm{O}^{-}$, making the zeolite with a more negatively charge (Kuzniatsova et al., 2007). Due the molecule size, SMX can diffuse into the micropores of FAU, and access to these adsorption sites, and promote the same interactions. A similar feature has been observed for other sulfonamide antibiotics adsorbed into FAU zeolite (Braschi et al., 2010; Blasioli et al., 2014).

For AZM, the adsorption is maximum at the $\mathrm{pH}$ value near to the molecule pKa (8.7) on both zeolites. At acid pH conditions, AZM occur predominantly in their protonated form via the tertiary amino group $\left(\left[-\mathrm{NH}\left(\mathrm{CH}_{3}\right)_{2}\right]\right)$ (Vajdle et al., 2017). Similar to SMX, the adsorption mechanism must be attributed to the electrostatic interaction and $\mathrm{H}$-bonding between the ionized and unionized molecules of AZM and $\equiv \mathrm{Si}-\mathrm{O}^{-}$groups on the zeolite surface. It can therefore be hypothesized that under these $\mathrm{pH}$ conditions, the adsorption process associated with electrostatic interactions on the zeolite surface could hinder the diffusion of AZM molecules into the zeolite channels, hence decreasing the adsorption efficiency. Unlike SMX, the AZM molecule is very large, and it is supposed that the adsorption involves mainly the external surface silanol groups
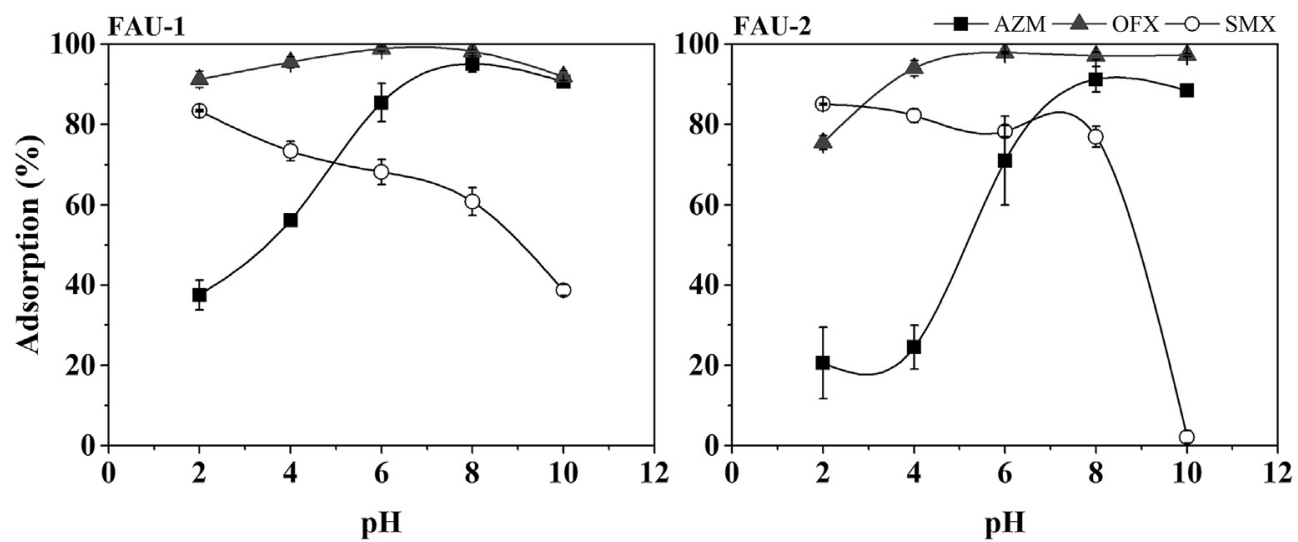

Fig. 4. Effect of solution $\mathrm{pH}$ on adsorption of the antibiotics onto FAU-1 and FAU-2. The error bars indicate the standard deviation $(\mathrm{n}=3$ ). 
Table 4

Langmuir and Freundlich non-linear isotherm parameters and coefficients of determination for adsorption of the antibiotics onto the FAU-1 and FAU-2 zeolites.

\begin{tabular}{|c|c|c|c|c|c|c|c|}
\hline \multirow[t]{2}{*}{ Antibiotic } & \multirow[t]{2}{*}{ Zeolite } & \multicolumn{3}{|c|}{ Langmuir equation } & \multicolumn{3}{|c|}{ Freundlich equation } \\
\hline & & $\mathrm{q}_{\mathrm{m}}\left(\mathrm{mg} \mathrm{g}^{-1}\right)$ & $\mathrm{K}_{\mathrm{L}}\left(\mathrm{L} \mathrm{mg}^{-1}\right)$ & $\mathrm{R}^{2}$ & $\overline{1 / n}$ & $\mathrm{~K}_{\mathrm{F}}\left(\mathrm{mg}^{1-1 / \mathrm{n}} \mathrm{L}^{1 / \mathrm{n}} \mathrm{g}^{-1}\right)$ & $\mathrm{R}^{2}$ \\
\hline \multirow[t]{2}{*}{ AZM } & FAU-1 & 8.50 & 29.93 & 0.847 & 0.448 & 15.31 & 0.785 \\
\hline & FAU-2 & 7.00 & 9146 & 0.693 & 0.106 & 9.40 & 0.831 \\
\hline \multirow[t]{2}{*}{ OFX } & FAU-1 & 31.32 & 37.43 & 0.573 & 0.573 & 190.31 & 0.499 \\
\hline & FAU-2 & 25.30 & 25.96 & 0.738 & 0.471 & 44.83 & 0.621 \\
\hline \multirow[t]{2}{*}{ SMX } & FAU-1 & - & - & - & 1.571 & 26.10 & 0.998 \\
\hline & FAU-2 & - & - & - & 1.847 & 105.46 & 0.994 \\
\hline
\end{tabular}

( $\equiv \mathrm{Si}-\mathrm{OH}$ ), due the difficult to this molecule access the acid sites Brønsted ( $\equiv \mathrm{Si}-\mathrm{OH}-\mathrm{Al} \equiv$ ) located into the zeolites micropores. Studies reported by other researchers (Martucci et al., 2012), show that the molecule of the analogous macrolide antibiotic erythromycin, slightly smaller than AZM, appears to be too large to interact directly and pass through the micropores on FAU-type zeolite, despite the presence of erythromycin inside the FAU cage was revealed by unit cell parameter variation and structural deformation using Rietveld method on zeolite after adsorption.

The results confirmed that the $\mathrm{pH}$-dependent speciation of antibiotics plays an important role in determining the adsorption efficiency. However, the results of the experiments without any $\mathrm{pH}$ adjustment showed that the three antibiotics presented relatively high adsorption efficiencies on both zeolites, so the subsequent adsorption isotherm experiments were performed at the original $\mathrm{pH}$ of the ultrapure water ( 6.5). An additional consideration is that on typical $\mathrm{pH}$ ranges of different environmental matrices like sewage, lake and river waters (Fatta-Kassinos et al., 2011). Overall, the optimum $\mathrm{pH}$ for antibiotic removal appeared to be about 6.5, which was the original $\mathrm{pH}$ of the ultrapure water.

\subsection{Adsorption isotherms}

Adsorption isotherms define the equilibrium relation between the quantity of the adsorbed material and the pressure or concentration in the bulk fluid phase at constant temperature (Dabrowski, 2001). Langmuir isotherm model is based on the assumption of homogeneous monolayer adsorption onto the surface with no re-adsorption of adsorbate on the surface and for Freundlich isotherm model, the stronger binding sites on the surface are occupied first and that the binding strength decreases with the increasing degree of site occupancy. Experiments to investigate the adsorption equilibrium were conducted at a fixed $\mathrm{pH}$ of 6.5 , according to results shown previously. The Langmuir and Freundlich isotherms were fitted to the experimental data, and the isotherm parameters obtained by non-linear fitting of Equations (5) and (6) are displayed in Table 4, along with the determinations coefficients $\left(R^{2}\right)$. Considering the values of $R^{2}$, a reasonable fitting for Freundlich model to the experimental data was obtained for the three antibiotics. Fig. 5 reports the experimental points of the adsorption experiments with Freundlich and Langmuir isotherms for FAU-2. A similar behavior was obtained for FAU-1, presented in Fig. S3.

The isotherms obtained with the zeolites were type $\mathrm{H}$ curves for AZM and OFX. This isotherm configuration is a particular case of type $\mathrm{L}$ isotherms, where the initial slope is very high, indicating that the compound exhibits a high affinity for the solid (Limousin et al., 2007). On the other hand, SMX presented a characteristic profile of a sub-group of type $\mathrm{S}$ curves, and can be associated to the moderated intermolecular attraction, (Giles et al., 1960). These results corroborate with kinetic evaluation, where a mass of zeolite 50 times higher was necessary to obtain a similar adsorption efficiency for SMX comparing to AZM and OFX, as show in Fig. 2.

Favorable adsorption is indicated by a value of $n$ between 1 and 10 , with a higher $n$ value (lower $1 / n$ ) reflecting stronger adsorbent/ adsorbate interaction, indicative of chemisorption. However, $1 / n$ values above 1 are indicative of cooperative adsorption (Foo and Hameed, 2010). Freundlich isotherms has been widely applied in heterogeneous systems especially for organic compounds or highly interactive species on activated carbon and molecular sieves (de Ridder et al., 2012; Nam et al., 2014; Calisto et al., 2015).

\subsection{Effect of a mixture of antibiotics on the adsorption process}

In investigation of the adsorption characteristics of a material, it is first necessary to understand the interactions between the adsorbent and individual adsorbates. However, in a real situation, the contaminants are present in mixtures containing a wide variety of chemical structures at different concentrations. In addition, other components from natural and/or anthropogenic origins can compete during the adsorption process, reducing the adsorption efficiency. Therefore, the efficiency of adsorption on FAU-1 was evaluated using a solution containing a mixture of the three antibiotics at initial concentrations of $50 \mu \mathrm{g} \mathrm{L}^{-1}$ of each antibiotic and the adsorbent at a concentration of $10 \mathrm{mg} \mathrm{L}^{-1}$ (Fig. 6).

Although the total concentration of the antibiotics in system $\left(150 \mu \mathrm{g} \mathrm{L}^{-1}\right)$ was higher than the initial concentration used in the kinetic experiments, the adsorption efficiencies presented a similar pattern compared to the adsorption efficiencies obtained in the earlier tests with individual antibiotic. In contrast, the adsorbed amount of SMX in zeolite, presented an increase in the mixture, whereas AZM and OFX presented a decrease (Fig. S4), compared to the individual tests. A similar behavior was reported for adsorption of pharmaceuticals in a mesoporous silica (Bui and Choi, 2009).

\subsection{Application of the zeolites using real samples}

Further investigation of the removal of the selected antibiotics onto the zeolites FAU-1 and FAU-2 was performed with a real wastewater sample. The effluent from the Girona WWTP was treated using FAU-1 and FAU-2, with quantification of the concentrations of the three antibiotics before and after the treatments. The results of the adsorption tests are presented in Table 5.

The wastewater effluent presented a value of $\mathrm{pH}$ of 7.25 and $10,98 \mathrm{mg} \mathrm{L}^{-1}$ of TOC. With respect to the presence of cations, the levels of some of them were $74,98 \mathrm{mg} \mathrm{L}^{-1}$ for $\mathrm{Na}^{+}, 1,19 \mathrm{mg} \mathrm{L}^{-1}$ for $\mathrm{NH}^{+}, 8,35 \mathrm{mg} \mathrm{L}^{-1}$ for $\mathrm{Mg}^{2+}$ and $57,83 \mathrm{mg} \mathrm{L}^{-1}$ for $\mathrm{Ca}^{2+}$. It can be seen from the data that the concentrations of AZM and OFX decreased by more than $50 \%$ using both zeolites, with OFX showing a maximum adsorption of $75 \%$, while adsorption of around $40 \%$ was observed for SMX. These results were very promising, considering that the wastewater sample contained a great variety of other 

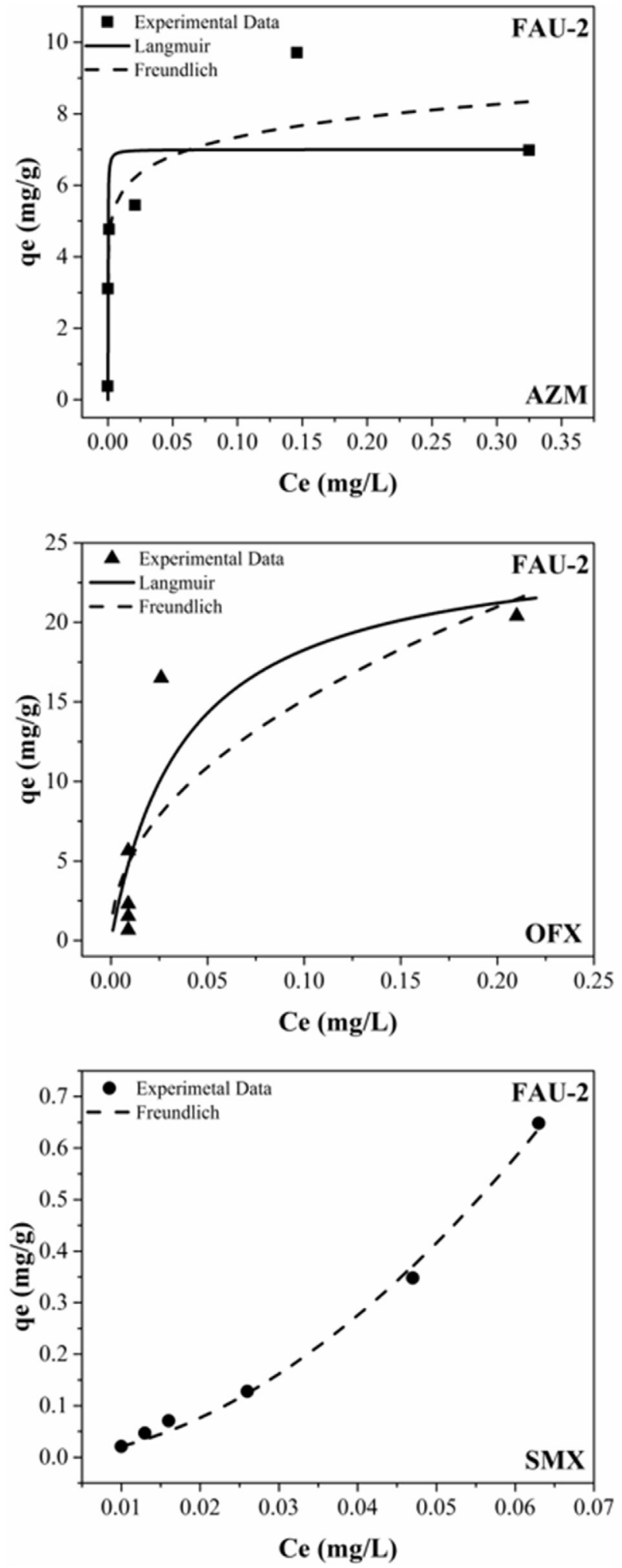

Fig. 5. Adsorption isotherms of AZM, OFX and SMX on FAU-1. The results were fitted to Langmuir and Freundlich equilibrium models.

contaminants, as detected in previous work (Gros et al., 2013), which were not investigated in the present study. Other components in the samples could also have competed with the target contaminants for the adsorption sites. Furthermore, considering

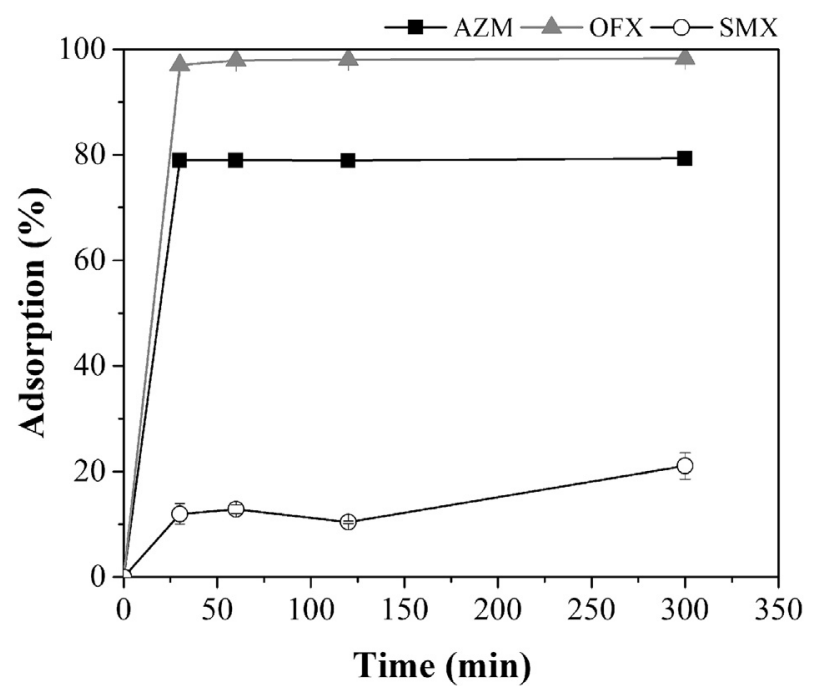

Fig. 6. Adsorption of a mixture of the three antibiotics onto zeolite FAU-1, as a function of contact time.

Table 5

Concentrations of the antibiotics in wastewater effluent, before and after adsorption on the FAU-1 and FAU-2 zeolites. Reaction conditions: zeolite concentration $=10 \mathrm{mg} \mathrm{L}^{-1}$; stirring time $=2 \mathrm{~h}$; sample $\mathrm{pH}=7.25$.

\begin{tabular}{llll}
\hline Antibiotic & Effluent WWTP $\left(\mathrm{ng} \mathrm{L}^{-1}\right)$ & \multicolumn{2}{l}{ Removal $(\%)$} \\
\cline { 3 - 4 } & & FAU-1 & FAU-2 \\
\hline AZM & 391 & 60.7 & 59.8 \\
OFX & 378 & 75.6 & 50.8 \\
SMX & 78.6 & 43.6 & 43.2 \\
\hline
\end{tabular}

the low adsorbent dosage employed here, the experimental conditions could be further optimized to maximize the adsorption.

\section{Conclusions}

The processes of adsorption of antibiotics of three different classes onto two FAU-type zeolites were studied under different conditions. Both FAU type zeolites showed highly effective removal of the antibiotics AZM, OFX and SMX, which were present at relatively high concentrations ( $\left.100 \mu \mathrm{g} \mathrm{L}^{-1}\right)$ compared to typical environmental concentrations measured in surface water and wastewater samples. For the tested zeolites, kinetics experiments revealed fast adsorption, which a dose of $10 \mathrm{mg} \mathrm{L}^{-1}$ was sufficient to achieve $\geq 80 \%$ contaminant removal for AZM and OFX within $30 \mathrm{~min}$, on both zeolites. The antibiotics AZM and SMX presented a pH-dependency, where the dominant adsorption mechanism is postulated to result from electrostatic interactions and $\mathrm{H}$-bonding. Results demonstrated that despite their different physicochemical characteristics, both zeolites are excellent candidates for the removal of contaminants of emerging concern in a real wastewater effluent sample.

Further investigations are required to assess of detailed adsorption process using zeolites aiming a better design of zeolite in a real scenario. Some considerations should be addressed in the future studies, including: the dominant interactions between contaminant-zeolite, as well as to improve the understanding of adsorption mechanism for several classes of contaminants; costbenefit analysis of zeolites application, mainly focus in their regeneration techniques for adsorbent recycling; studies must be preferentially performed at environmental relevant concentrations and using more complex multicomponent mixtures of 
contaminants; and carry out some pilot-plant scale studies considering the integration of adsorption process into existing WWTP design. Most probably, a key factor in the adsorption efficiency performed by zeolite will be the degree of success of the conventional secondary and tertiary WWTP in removing organic matter and nutrients.

\section{Acknowledgments}

The authors thank the São Paulo State Research Foundation grants \#2016/01314-7 and \#2014/11952-5. We are grateful to Zeolyst International for the donation of materials. This work was supported by the Generalitat de Catalunya (Consolidated Research Groups: ICRA 2014 SGR 291).

\section{Appendix A. Supplementary data}

Supplementary data related to this article can be found at https://doi.org/10.1016/j.chemosphere.2018.04.085.

\section{References}

Azizian, S., 2004. Kinetic models of sorption: a theoretical analysis. J. Colloid Interface Sci. 276, 47-52. https://doi.org/10.1016/j.jcis.2004.03.048.

Baerlocher, C., Meier, W.M., Olson, D.H., 2017. Atlas of Zeolite Framework Types, Sixth Revised Edition. Elsevier, Amsterdam.

Blasioli, S., Martucci, A., Paul, G., Gigli, L., Cossi, M., Johnston, C.T., Marchese, L., Braschi, I., 2014. Removal of sulfamethoxazole sulfonamide antibiotic from water by high silica zeolites: a study of the involved host - guest interactions by a combined structural, spectroscopic, and computational approach. J. Colloid Interface Sci. 419, 148-159. https://doi.org/10.1016/j.jcis.2013.12.039.

Braschi, I., Blasioli, S., Gigli, L., Gessa, C.B., Alberti, A., Martucci, A., 2010. Removal of sulfonamide antibiotics from water: evidence of adsorption into an organophilic zeolite Y by its structural modifications. J. Hazard Mater. 178, 218-225. https://doi.org/10.1016/j.jhazmat.2010.01.066.

Bui, T.X., Choi, H., 2009. Adsorptive removal of selected pharmaceuticals by mesoporous silica SBA-15. J. Hazard Mater. 168, 602-608. https://doi.org/10.1016/ j.jhazmat.2009.02.072.

Bui, T.X., Pham, V.H., Le, S.T., Choi, H., 2013. Adsorption of pharmaceuticals onto trimethylsilylated mesoporous SBA-15. J. Hazard Mater. 254-255, 345-353. https://doi.org/10.1016/j.jhazmat.2013.04.003.

Calisto, V., Ferreira, C.I.A., Oliveira, J.A.B.P., Otero, M., Esteves, V.I., 2015. Adsorptive removal of pharmaceuticals from water by commercial and waste-based carbons. J. Environ. Manag. 152, 83-90. https://doi.org/10.1016/ j.jenvman.2015.01.019.

Carrales-Alvarado, D.H., Ocampo-Pérez, R., Leyva-Ramos, R., Rivera-Utrilla, J., 2014. Removal of the antibiotic metronidazole by adsorption on various carbon materials from aqueous phase. J. Colloid Interface Sci. 436, 276-285. https:/ doi.org/10.1016/j.jcis.2014.08.023.

Carvalho, I.T., Santos, L., 2016. Antibiotics in the aquatic environments: a review of the European scenario. Environ. Int. 94, 736-757. https://doi.org/10.1016/ j.envint.2016.06.025.

Chaves, T.F., Pastore, H.O., Cardoso, D., 2012. A simple synthesis procedure to prepare nanosized faujasite crystals. Microporous Mesoporous Mater. 161 https:/ doi.org/10.1016/j.micromeso.2012.05.022.

Chen, Y., 1999. The investigation on the crystallinity of USY zeolite during hydrothermal dealumination. In: Shape-selective Catalysis, ACS Symposium Series. American Chemical Society, pp. 23-322. https://doi.org/10.1021/bk-20000738.ch023.

Cincinelli, A., Matellini, T., Coppini, E., Fibbi, D., Katsoyiannis, A., 2015. Nanotechnologies for removal of pharmaceuticals and personal care products from water and wastewater. A Review. J. Nanosci. Nanotechnol. 15, 3333-3347. https:/ doi.org/10.1166/jnn.2015.10036.

Cundy, C.S., Cox, P.A., 2003. The hydrothermal synthesis of zeolites: history and development from the earliest days to the present time. Chem. Rev. 103, 663-702. https://doi.org/10.1021/cr020060i.

Dabrowski, A., 2001. Adsorption - from theory to practice. Adv. Colloid Interface Sci. 93, 135-224.

Daughton, C.G., Ternes, T.A., 1999. Pharmaceuticals and personal care products in the environment: agents of subtle change? Environ. Health Perspect. 107 (Suppl. 1), 907-938.

Davis, M.E., Lobo, R.F., 1992. Zeolite and molecular sieve synthesis. Chem. Mater. 4, 756-768. https://doi.org/10.1021/cm00022a005.

de Ridder, D.J., Verberk, J.Q.J.C., Heijman, S.G.J., Amy, G.L., van Dijk, J.C., 2012. Zeolites for nitrosamine and pharmaceutical removal from demineralised and surface water: mechanisms and efficacy. Sep. Purif. Technol 89, 71-77. https:// doi.org/10.1016/j.seppur.2012.01.025.

Directive, 2015. 2013/495/EU of the European Parliament and of the Council of 20
March 2015 establishing a watch list of substances for Union-wide monitoring in the field of water policy pursuant to Directive 2008/105/EC of the European Parliament and of the Council. Off. J. Eur. Union. L78/40-42.

Ebie, K., Li, F., Azuma, Y., Yuasa, A., Hagishita, T., 2001. Pore distribution effect of activated carbon in adsorbing organic micropollutants from natural water. Water Res. 35, 167-179. https://doi.org/10.1016/S0043-1354(00)00257-8.

Farré, M.J., Insa, S., Mamo, J., Barceló, D., 2016. Determination of 15 N-nitrosodimethylamine precursors in differentwater matrices by automated on-line solid-phase extractionultra-high-performance-liquid chromatography tandem massspectrometry. J. Chromatog. A. 1458, 99-111. https://doi.org/10.1016/ j.chroma.2016.06.064.

Fatta-Kassinos, D., Meric, S., Nikolaou, A., 2011. Pharmaceutical residues in environmental waters and wastewater: current state of knowledge and future research. Anal. Bioanal. Chem. 399, 251-275. https://doi.org/10.1007/s00216010-4300-9.

Fent, K., Weston, A. a, Caminada, D., 2006. Ecotoxicology of human pharmaceuticals. Aquat. Toxicol. 76, 122-159. https://doi.org/10.1016/j.aquatox.2005.09.009.

Foo, K.Y., Hameed, B.H., 2010. Insights into the modeling of adsorption isotherm systems. Chem. Eng. J. 156, 2-10. https://doi.org/10.1016/j.cej.2009.09.013.

Fukahori, S., Fujiwara, T., Ito, R., Funamizu, N., 2011. pH-Dependent adsorption of sulfa drugs on high silica zeolite: modeling and kinetic study. Desalination 275, 237-242. https://doi.org/10.1016/j.desal.2011.03.006.

García-galán, M.J., Díaz-cruz, M.S., Barceló, D., 2011. Occurrence of sulfonamide residues along the Ebro river basin Removal in wastewater treatment plants and environmental impact assessment. Environ. Int. 37, 462-473. https:// doi.org/10.1016/j.envint.2010.11.011.

Genç, N., Dogan, E.C., 2015. Adsorption kinetics of the antibiotic ciprofloxacin on bentonite, activated carbon, zeolite, and pumice. Desalin. Water Treat 53, 785-793. https://doi.org/10.1080/19443994.2013.842504.

Giles, C.H., MacEwan, T.H., Nakhwa, S.N., Smith, D., 1960. Studies in adsorption. Part XI. A system of classification of solutions adsorption isotherms, and its use in diagnosis of adsorption mechanisms and in measurement of specific surface areas of solids. J. Chem. Soc. 111, 3973-3993. https://doi.org/10.1039/ jr9600003973.

Gounder, R., Jones, A.J., Carr, R.T., Iglesia, E., 2012. Solvation and acid strength effects on catalysis by faujasite zeolites. J. Catal. 286, 214-223. https://doi.org/10.1016/ j.jcat.2011.11.002.

Gros, M., Rodríguez-mozaz, S., Barceló, D., 2013. Rapid analysis of multiclass antibiotic residues and some of their metabolites in hospital, urban wastewater and river water by ultra-high-performance liquid chromatography coupled to quadrupole-linear ion trap tandem mass spectrometry. J. Chromatogr. A 1292, 173-188. https://doi.org/10.1016/j.chroma.2012.12.072.

Holmberg, B.A., Wang, H., Norbeck, J.M., Yan, Y., 2003. Controlling size and yield of zeolite $\mathrm{Y}$ nanocrystals using tetramethylammonium bromide. Microporous Mesoporous Mater. 59, 13-28. https://doi.org/10.1016/S1387-1811(03)00271-3.

Homem, V., Santos, L., 2011. Degradation and removal methods of antibiotics from aqueous matrices e A review. J. Environ. Manag. 92, 2304-2347. https://doi.org/ 10.1016/j.jenvman.2011.05.023.

Kacirek, H., Lechert, H., 1975. Growth of the zeolite type NaY. J. Phys. Chem. 79, 1589-1593. https://doi.org/10.1021/j100582a024.

Kulprathipanja, S., 2010. Aspects of mechanisms, processes, and requirements for zeolite separation. In: Kulprathipanja, S. (Ed.), Zeolites in Industrial Separation and Catalysis. Wiley-VCH Verlag GmbH \& Co. KGaA, pp. 203-228. https:// doi.org/10.1002/9783527629565.ch6.

Kuzniatsova, T., Kim, Y., Shqau, K., Dutta, P.K., Verweij, H., 2007. Zeta potential measurements of zeolite Y: application in homogeneous deposition of particle coatings. Microporous Mesoporous Mater. 103, 102-107. https://doi.org/ 10.1016/j.micromeso.2007.01.042.

Limousin, G., Gaudet, J.-P., Charlet, L., Szenknect, S., Barthès, V., Krimissa, M., 2007. Sorption isotherms: a review on physical bases, modeling and measurement. Appl. Geochem. 22, 249-275. https://doi.org/10.1016/j.apgeochem.2006.09.010.

Martucci, A., Pasti, L., Marchetti, N., Cavazzini, A., Dondi, F., Alberti, A., 2012. Adsorption of pharmaceuticals from aqueous solutions on synthetic zeolites. Microporous Mesoporous Mater. 148, 174-183. https://doi.org/10.1016/ j.micromeso.2011.07.009.

Michael, I., Rizzo, L., Mcardell, C.S., Manaia, C.M., Merlin, C., Schwartz, T., Dagot, C., Fatta-kassinos, D., 2012. Urban wastewater treatment plants as hotspots for the release of antibiotics in the environment: a review. Water Res. 47, 957-995. https://doi.org/10.1016/j.watres.2012.11.027.

Nam, S.-W., Choi, D.-J., Kim, S.-K., Her, N., Zoh, K.-D., 2014. Adsorption characteristics of selected hydrophilic and hydrophobic micropollutants in water using activated carbon. J. Hazar. Mater 270, 144-152. https://doi.org/10.1016/ j.jhazmat.2014.01.037.

Pelekani, C., Snoeyink, V., 1999. Competitive adsorption in natural water: role of activated carbon pore size. Water Res. 33, 1209-1219. https://doi.org/10.1016/ S0043-1354(98)00329-7.

Perego, C., Bagatin, R., Tagliabue, M., Vignola, R., 2013. Zeolites and related mesoporous materials for multi-talented environmental solutions. Microporous Mesoporous Mater. 166, 37-49. https://doi.org/10.1016/ j.micromeso.2012.04.048.

Sophia A, C., Lima, E.C., 2018. Removal of emerging contaminants from the environment by adsorption. Ecotoxicol. Environ. Saf. 150, 1-17. https://doi.org/ 10.1016/j.ecoenv.2017.12.026.

Vajdle, O., Guzsvány, V., Škorić, D., Csanádi, J., Petković, M., Avramov-Ivić, M., Kónya, Z., Petrović, S., Bobrowski, A., 2017. Voltammetric behavior and 
determination of the macrolide antibiotics azithromycin, clarithromycin and roxithromycin at a renewable silver -amalgam film electrode. Electrochim. Acta 229, 334-344. https://doi.org/10.1016/j.electacta.2017.01.146.

Weitkamp, J., 2000. Zeolites and catalysis. Solid State Ionics 131, 175-188. https:/ doi.org/10.1016/S0167-2738(00)00632-9.

Yang, W., Wang, X., Tang, Y., Wang, Y., Ke, C., Fu, S., 2002. Layer-by-layer assembly of nanozeolite based on polymeric microsphere: zeolite coated sphere and hollow zeolite sphere. J. Macromol. Sci. Pure Appl. Chem. 39 (6), 509-526. https:/ doi.org/10.1081/MA-120004244.

Yu, F., Li, Y., Han, S., Ma, J., 2016. Adsorptive removal of antibiotics from aqueous solution using carbon materials. Chemosphere 153, 365-385. https://doi.org 10.1016/j.chemosphere.2016.03.083. 